\title{
Temporary Employment, Permanent Stigma? Perceptions of Temporary Agency Workers Across Low- and High-Skilled Jobs
}

\author{
Pia Cardone \\ Chemnitz University of Technology, Germany \\ Markus Tümpel \\ Chemnitz University of Technology, Germany \\ Christian M. Huber \\ Chemnitz University of Technology, Germany
}

DOI: https://doi.org/10.18778/1733-8077.17.3.01

\section{Keywords:}

Employment Status; Intergroup Relations; Skill-Level; Stigma; Temporary Agency Workers

\begin{abstract}
Research on temporary agency work emphasizes that temporary agency workers (TAWs), particularly those in low-skilled jobs associated with precariousness and low social prestige, are likely to be exposed to poor treatment, as well as stigmatization. On the contrary, stigmatization of TAWs in high-skilled jobs has not been treated in much detail in previous studies. Literature provides an incomplete picture of stigmatization within the broader field of temporary employment regarding the focus on low-skilled jobs. Hence, the present qualitative study is based on data from interviews of a heterogeneous sample of TAWs employed in low- and high-skilled jobs in Germany. By using and modifying Boyce and colleagues' (2007) model of stigmatization, the study shows that stigmatizing treatment towards TAWs occurs across all skill levels, although the intensity and form of those experiences, as well as coping strategies, differ. Thereby, this study contributes to a more differentiated and skill level-specific understanding of how TAWs perceive and cope with stigmatization linked to their employment status. It also provides an important opportunity to advance Boyce and colleagues' (2007) complex model of TAW stigmatization with empirical underpinnings.
\end{abstract}

Pia Cardone is a research associate of Organization Studies at the Professorship of Organization and International Management at the Chemnitz University of Technology. Her main research areas include social inequality, effects of intraorganizational figurations, and processes of in- and exclusion in organizations. Her research follows an interdisciplinary approach, represented in publications and conference contributions in the fields of sport sociology, migration, and management research. She currently defended her doctoral thesis titled Social Inequality in Organizations-Empirical Studies on the Emergence and Reproduction of Social Inequality in Organizational Contexts. email address: pia.cardone@wirtschaft.tu-chemnitz.de 
Markus Tümpel is a research associate at the Chemnitz University of Technology at the Faculty of Economics and Business Administration. He completed an MA in Sociocultural Studies and is currently working on his Ph.D. His fields of research are self-employment and precariousness, participation, deviance, and alternative forms of organization. He recently co-authored a study on participation practices in German cooperatives.

email address: markus.tuempel@wirtschaft.tu-chemnitz.de
Christian M. Huber is a research associate and a Ph.D. Candidate at the Chair of Organization and International Management, Faculty of Economics and Business Administration, Chemnitz University of Technology, Germany. He received his M.Sc. in Management and Organization Studies from Chemnitz University of Technology, Germany. His research interests include environmental, as well as social sustainability in organizations.

email address: christian.huber@wirtschaft.tu-chemnitz.de

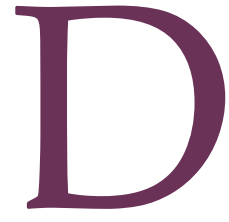
espite its theoretical and practical relevance, research on stigmatization in organizational settings is rather scarce (Summers et al. 2018). Organizations represent social spaces with specific power relations and inequalities that provide a breeding ground for stigma phenomena. A relationship deeply embedded in the power structures and functioning of organizations is the one between permanent and temporary workers (Boyce et al. 2007; Rybnikova and Cardone 2018). Temporary agency workers (TAWs) hold a lower position in client firms than the core workforce because of inferior working conditions. This issue has been frequently addressed in amendments of legal regulations and union actions across the globe to improve TAWs' job security and equal treatment (see: Pulignano and Doerflinger 2013; Keune and Pedaci 2020). Although these efforts have led to improvements, TAWs remain disadvantaged and short-term employment, less favorable work activities, lower wages, and benefits, lack of career opportunities, as well as separation on an artifact level, result in a disproportionate amount of power given to permanent workers within organizations using temporary agency work (henceforth referred to as client firms) (Rybnikova and Cardone 2018).
Research on occupational stigma has predominantly focused on forms of stigmatization linked to occupations with low prestige, associated with low status, power, quality of work, education or income, and on how people cope with the stigmas that are brought on to them because of their work status (Kreiner, Ashforth, and Sluss 2006; Benoit, McCarthy, and Jansson 2015; Bosmans et al. 2016; Benoit et al. 2019). Stigma research has also highlighted that occupational stigma is particularly dangerous, as an occupation is crucial to an individual's self-presentation and is perceived to be controllable (Volpato, Andrighetto, and Baldissarri 2017). Work status, as opposed to other social categories such as ethnicity, gender and sex, or physical inability that are seen as inevitable, is believed to be chosen by those affected and thus makes them responsible for their own "misery" (Crandall 2000). Occupational stigma research has been criticized for considering a variety of occupations under the umbrella of "dirty work," referring to occupations that are somehow socially, physically, or morally tainted, without emphasizing the differences between them (Kreiner et al. 2006). This might also be an explanation why stigma research has made only a few attempts to address particular occupational fields or specific forms of work arrangements such 
as temporary agency work. However, an exception represents the study of Boyce and colleagues (2007) that, based on a large corpus of literature, proposes a comprehensive model of TAW stigmatization, including organizational conditions, perpetrator motives, forms of stigmatization, as well as stigma perceptions and consequences. Their model comprises a large number of relevant factors and thus provides an adequate basis for empirical studies aimed at understanding the various facets of stigmatization in organizations. Yet, despite the study of Boyce and colleagues (2007), research on temporary work lacks empirical evidence in regard to understanding stigma phenomena. However, several studies indicate a marginalization of TAWs as an inferior group of organizational actors associated with negative attributes including a low skill set, lack of intelligence, or weak work ethic (Byoung-Hoon and Frenkel 2004; Bosmans et al. 2015a; Helfen, Hense, and Nicklich 2015; Rybnikova and Cardone 2018; Stasiowski and Kłobuszewska 2018). Thus, jobs through temporary agency work have been identified as socially tainted (Boyce et al. 2007; Winkler and Mahmood 2018), and there is evidence for higher risk of experiences of bullying for workers in these occupations (Djurkovic 2018). Generally speaking, the prevalence of bullying is significantly higher for unskilled workers (Ortega et al. 2009; Lange et al. 2019). Consequently, this applies to a large proportion of temporary workers, of which, in Germany, 31\% have no professional qualification and even more (54\%) are doing unskilled work (BA 2020).

Furthermore, recent research has highlighted the negative effects of employment status on TAWs' well-being, health, job satisfaction, and commitment (Bosmans et al. 2015b; Chambel, Castanheira, and Sobral 2016; Borgogni, Consiglio, and Di Tecco 2016; Aleksynska 2018; Imhof and Andresen 2018; Stasio- wski and Kłobuszewska 2018; Hünefeld, Gerstenberg, and Hüffmeier 2020). Nevertheless, the findings of previous studies on temporary agency work show an ambivalent picture regarding the experience of poor treatment within client firms, indicating that it is not solely employment status causing these experiences. Other reasons can include the working conditions, particularly in competitive work environments in which permanent workers perceive TAWs as a threat, the stigmatizing treatment of TAWs can become a function of permanent workers trying to maintain their superior status (Boyce et al. 2007; Becker 2015; Bosmans et al. 2015a; Stasiowski and Kłobuszewska 2018). Notwithstanding TAWs' disadvantages compared to permanent employees that are predefined by the legal framework (e.g., lower wages, higher uncertainty), client firms have a certain degree of freedom to interpret legal regulations and organize the use of TAWs. Consequently, they have the power to establish management policies that shape the interactions between permanent workers and TAWs (Boyce et al. 2007; Becker 2015).

Furthermore, experiences of stigmatization depend on the individual and might differ according to the TAWs' circumstances, their skill-level, and whether they are voluntarily or involuntarily employed in temporary agency work (Sitte and Lehmann 2013; Selvarajan, Slattery, and Stringer 2015; Bryant and McKeown 2016; Stasiowski and Kłobuszewska 2018). The legal and institutional framework of their employment, with respect to compensation, length of employment, and training opportunities, differs significantly depending on whether they are employed in high-skilled or low-skilled jobs (Sitte and Lehmann 2013; Bryant and McKeown 2016). Sitte and Lehmann (2013) classify TAWs according to the required job qualifications in low-skilled positions as helpers (perform activities for which no complet- 
ed vocational training is required) and high-skilled positions as specialists (perform activities for which completed vocational training is a prerequisite, but no academic studies), and academics (perform activities for which academic studies are a prerequisite), a classification adopted in the present study.

Previous empirical research on TAWs' integration in client firms has either focused on low-skilled (Boyce et al. 2007; Bosmans et al. 2015a; Rybnikova and Cardone 2018) or on high-skilled jobs (Augustsson 2014; 2016; Bryant and McKeown 2016). While TAWs in low-skilled jobs are mainly associated as powerless, involuntarily employed workers likely to be exposed to stigmatizing treatment by their permanent employed colleagues (Boyce et al. 2007; Rybnikova and Cardone 2018), high-skilled TAWs are identified as professionals that are voluntarily employed in agency work and have a high degree of autonomy in their decisions (Kunda, Barley, and Evans 2002; Vallas and Prener 2012). Bosmans and colleagues (2015a) even hypothesize that TAWs in high-skilled jobs who enter client firms as experts are hardly affected by stigmatization. Previous studies, that have mainly considered TAWs in low-skilled jobs to be at risk of experiencing stigmatization, provide an incomplete picture of stigmatization in the broader field of temporary employment. Bryant and McKeown (2016:390), who analyzed the effects of the use of TAWs with different motives and skill levels on the social capital of client firms, also emphasized that TAWs' "experiences are more nuanced and ambiguous than how they are often presented in the literature." Their qualitative study with TAWs employed as IT experts revealed the struggles of highly skilled TAWs who identified themselves not only as experts but also as outsiders and strangers in client firms. Addressing this issue, this study aims to provide insights into stigmatization experiences of TAWs engaged in both low- as well as high-skilled jobs and answer the following research question: How do TAWs across different job skill levels perceive and cope with employment status-based stigmas?

This research question is approached by adapting and modifying Boyce and colleagues' model of TAW stigmatization and analyzing collected data from 16 interviews with TAWs. Our sample consists of TAWs of different ages, gender, and work experiences in low- and high-skilled jobs from independent temporary employment firms in Germany. The importance and originality of this study are that it explores the stigmatization that TAWs experience with regard to the skill level of their position. Moreover, this project provides an important opportunity to advance the empirical underpinnings of Boyce and colleagues' (2007) complex model. This study shows the multifaceted range of stigmatization experiences from subtler to more direct forms and takes a critical look at the working environment of client firms in Germany.

\section{Theory}

Our analysis is based on the conceptual framework proposed by Boyce and colleagues (2007). They developed a model comprising the organizational conditions and consequences of the stigmatization of TAWs. With this holistic approach, they offer an analytical framework for critically studying the organizational practices that might lead to the poor treatment of TAWs (Boyce et al. 2007). Using this framework empirically to provide knowledge on TAWs' experiences of stigmatization may help "to ensure that the financial gains anticipated through the use of temporary workers are not offset by any negative consequences that result from these workers being treated in a stigmatized manner on the job" (Boyce et al. 2007: 6). In particular, we focus 
on the following areas that guide our study: work environment, stigmatizing treatment, perception of stigma, and coping strategies. These categories are described and underpinned with findings from recent research in the next section.

\section{Work Environment}

Boyce and colleagues (2007) subdivide stigmatization into three basic conditions: perceptions of perpetrators, characteristics of the worker (referring to the visibility of their employment status), and characteristics of the work environment. Theoretically, it is plausible to separate these factors, but empirically it is reasonable to more closely consider the interdependencies between them. Hence, this study-contrary to Boyce and colleagues'-subsumes and discusses all three aspects under the umbrella of the work environment. The work environment is crucial for stigma phenomena as a stigma is a socially constructed perception of being tainted that is highly context-dependent. While a social category might be associated with negative stereotypes and beliefs in one context, the social category might not be considered tainted in another (Thomson and Grandy 2018). TAWs' stigmatization addresses the employment status as a socially tainted category, which is strongly embedded in the power structures and functions of an organization (Boyce et al. 2007). Not every work environment triggers stigmatizing treatment against TAWs on a social level. Legal regulations provide a framework for the employment of TAWs that already perpetuates the disadvantages for them as compared to permanent workers. However, client firms still have the freedom to frame their respective work arrangements (Becker 2015). Empirical studies provide evidence that management practices and policies are influencing the occurrence of interpersonal conflicts between temporary and permanent workers, as well as the power potentials of both groups (Byoung-Hoon and Frenkel 2004; Håkansson and Isidorsson 2012; Viitala and Kantola 2016; Rybnikova and Cardone 2018). According to Viitala and Kantola (2016), this finding holds true for both, low- and high-skilled jobs. Håkansson and Isidorsson (2012) show that labor portfolios in the context of temporary agency work are diverse and determined by client firms' policies in regard to employment duration, assigned tasks, and access to training for TAWs. Depending on how different the tasks between TAWs and permanent employees are and how closely their activities are interrelated, the separation between permanent workers and TAWs is weaker or stronger. Another factor that is decisively influenced by management policy is the visibility of employment status. Boyce and colleagues (2007) suggest that stigmatizing treatment towards TAWs is stronger in work settings in which TAWs are easily identifiable. Some companies reinforce their separation from the core workforce on an artifact level, for example, through different dress codes (Rybnikova and Cardone 2018). Client firm management can organize the use of TAWs and their integration in the organization differently, for example, through the workload, work allocation, length of employment, access to resources, formal and informal norms of equal treatment, or visible differentiation based on working status (Bosmans et al. 2015a; Rybnikova and Cardone 2018). Because of different everyday practices in dealing with TAWs, it is possible to promote solidarity or exclusionary behavior in the permanent workforce (Viitala and Kantola 2016; Rybnikova and Cardone 2018).

In addition to the diversity of activities and interdependencies in the work relations between temporary and permanent employees, Byoung-Hoon and Frenkel (2004) emphasize that a company's history plays an important role in the conflicts between temporary 
and permanent workers. Established conflict structures in client firms increase the tendency to discriminate against TAWs. Previous research findings further indicate that interpersonal problems are mainly an issue in organizations using extensive temporary work for cost reduction and to create a highly competitive climate between their permanent and temporary workforces. Depending on how organizations handle the use of TAWs, permanent workers can see them as competitors or a helping hand (Schwaab and Durian 2017). So far, the work environment has proven to be relevant to the stigmatization of TAWs.

\section{Stigmatizing Treatment}

Stigmatizing treatment does not occur in a vacuum; it serves the perpetrators to help achieve their goals. So far, the perceptions of perpetrators, such as permanent workers and management, play a relevant role in the existence of stigmatization in client firms. Both management and permanent workers may favor excluding and discriminating against TAWs to maintain their power and define a target for downward comparison (Boyce et al. 2007; Becker 2015; Rybnikova and Cardone 2018). Through alliance building, management and permanent workers can stabilize the inferior position of TAWs (Byoung-Hoon and Frenkel 2004). Nevertheless, interdependencies in the work processes and social interactions between the worker groups often put permanent workers in a dilemma between showing solidarity and reacting in a stigmatizing manner to the perceived threat (Bosmans et al. 2015a; Rybnikova and Cardone 2018). As Boyce and colleagues (2007) suggest, the social norms of acceptance also determine the extent to which permanent workers treat TAWs in a stigmatizing way and what forms of stigmatizing treatment they adopt. According to Boyce and colleagues (2007), stigmatizing treatment occurs in both overt and covert forms. While overt stigmatization includes direct statements regarding inferiority linked to employment status, the more subtle, covert forms can occur as nonverbal expressions, such as avoiding eye contact or withholding resources or information (Boyce et al. 2007). Flemnitz (2018) found that when compared to their permanently employed colleagues, TAWs are hindered in their work by being denied access rights and by being confronted with poorer work conditions, including working on short notice, holiday restrictions, unpleasant tasks, or not receiving benefits. Holm, Torkelson, and Bäckström (2016) provide similar evidence for the poor treatment of TAWs, showing that they often have less access to information, are excluded from professional camaraderie, and are mainly used to do undesirable work. In addition to the more covert forms of stigmatization, TAWs also report stronger and more overt forms of poor treatment, speaking of being exposed to derogatory comments from their permanent colleagues, being bullied, or threatened with physical abuse (Holm et al. 2016). While those disadvantages have been empirically emphasized in the context of low-skilled jobs, highly-skilled TAWs were mainly identified to receive less learning and networking opportunities, to be kept out of decision-making processes (Augustsson 2014; 2016), and to be less likely asked for advice (Wilkin, de Jong, and Rubino 2018). Overtly hostile behavior has not been mentioned in this context. Regardless of the level at which stigmatization takes place and whether it is overt or covert, it essentially serves three objectives: to keep people down (domination), to keep people in line (avoid norm violation), or to keep people away (maintaining exclusiveness) (Link and Phelan 2014). Tyler and Slater (2018) emphasize that most concepts of stigma based on Goffman's classic approach often sideline "questions about where stigma is produced, by 
whom, and for what purposes" (Goffman 1990:721). While Boyce and colleagues (2007) considered the perpetrators' motives in their analytical framework, Tyler and Slater (2018) still criticize the missing account of the inner organizational power structures that shape the perpetrators' motives.

\section{Perception of Stigma}

Stigma, in contrast to prejudice, considers the actual perception of the people affected. Boyce and colleagues (2007) identify five moderating factors believed to have an influence on stigma perception: the perceived perpetrator's motive, the justifiability of poor treatment, stigma consciousness, group identification, and employment status congruence. Poor treatment is not necessarily linked to employment status (Boyce et al. 2007). If TAWs associate poor behavior towards them with other reasons, such as a generally harsh attitude in the company, this behavior has no stigmatizing effect (Flemnitz 2018). Justifiability determines the perception of stigma as follows; if TAWs perceive the treatment towards them as legitimate, for example, because it is in line with the communicated management policy and their expectations, this treatment barely develops a stigmatizing nature (Boyce et al. 2007). Chambel and colleagues (2016) found that TAWs tend to have lower expectations of client companies' efforts and treatment towards them, and, consequently, often interpret poor treatment as in line with their expectations. If client companies establish policies in favor of TAWs, they perceive these policies as exceptionally positive (Chambel et al. 2016). However, if poor treatment is perceived as unjust, it is likely to be perceived as stigmatizing (Boyce et al. 2007). The perception of being stigmatized also goes along with a conscious identification of employment status as a criterion for discrimination and deval- uation. TAWs who see their employment status as a tainted social category are more likely to interpret their experiences within a company based on this assumption. As a consequence, they most likely define poor treatment towards them as stigmatizing (Boyce et al. 2007). Furthermore, the ambiguity in how TAWs identify themselves has been highlighted in several studies. Both TAWs employed in lowand high-skilled jobs identify themselves simultaneously as employees with valuable knowledge and expertise, and as outsiders, whose knowledge is neglected (Bryant and McKeown 2016; Winkler and Mahmood 2018). However, as a self-protective coping strategy, highly-skilled TAWs are more likely to define themselves as autonomous, self-directed employees seeking freedom from conventional work arrangements (Bryant and McKeown 2016). In addition, identification with employment status is important for the perception of stigma. According to Boyce and colleagues (2007), TAWs who see their employment status as a core part of their identity are more likely to perceive poor treatment as related to this attribute than others who are not as strongly committed to this social category. Previous research also suggests that gender affects stigma perception. Selvarajan and colleagues (2015) found that men see their job as more central to their identity than women, and, consequently, are more likely to perceive their status as a TAW as stigmatizing. As previously stated, TAWs are by no means a homogenous group. According to their life situations, personal attitude, motives for accepting temporary employment, or their qualification levels, TAWs might attach varying importance to how they are treated in a client firm (Selvarajan et al. 2015; Flemnitz 2018; Stasiowski and Kłobuszewska 2018). Those working voluntarily for a temporary work agency and who make sense of their work as something that gives them flexibility will have greater employment status congruence 
and, consequently, may draw less attention to how they are treated by their permanent colleagues or client firm management (Boyce et al. 2007). Moreover, Bosmans and colleagues (2015a) assume that higher-skilled TAWs more easily accept their employment status and have fewer difficulties going along with it than lower-skilled TAWs.

\section{Coping Strategies}

Boyce and colleagues (2007) refer to various outcomes of stigmatizing treatment for TAWs. Mainly, they address consequences for the well-being, job satisfaction, commitment, mood, and job-related behaviors of TAWs in response to perceived poor treatment (Boyce et al. 2007). Current empirical studies also provide evidence for negative effects, especially on the job satisfaction, commitment, and well-being (Boswell et al. 2012; Borgogni et al. 2016; Aleksynska 2018; Imhof and Andresen 2018; Stasiowski and Kłobuszewska 2018). In contrast, however, Winkler and Mahmood (2018) found that TAWs respond to poorer working conditions compared to permanently employed workers by a rapid adaption and demonstration of willingness to safeguard their positive self-image and impress client firms. Responses to stigmatization might be of a passive or active nature. Based on their literature review, Boyce and colleagues (2007) refer to a lack of research on more active coping strategies used by TAWs. One reason for the little empirical evidence of active response strategies might be that the coping resources of TAWs are limited due to their potential exclusion from social networks, a lack of representation by trade unions, or perceived mistrust within organizations (Bosmans et al. 2015a). Still, Boyce and colleagues (2007) refer to collective action, problem-solving, or organizational citizenship behavior as active responses. There is, however, evidence that TAWs might develop different coping strategies due to their situations and employment sectors. For example, Bosmans and colleagues (2015a) highlight the differences between higher- and lower-skilled agency workers in coping with stigmatization. As they more often have purposefully chosen their work arrangement, TAWs in higher positions appear to have fewer difficulties in dealing with their employment status. Also, they are more likely to be offered opportunities for training and learning (Bosmans et al. 2015a). Taking into consideration the above-mentioned theoretical remarks, we used a condensed version of Boyce and colleagues' (2007) model of TAW stigmatization as a starting point for our fieldwork. This model is shown in Figure 1.

Figure 1. Condensed model of TAW stigmatization

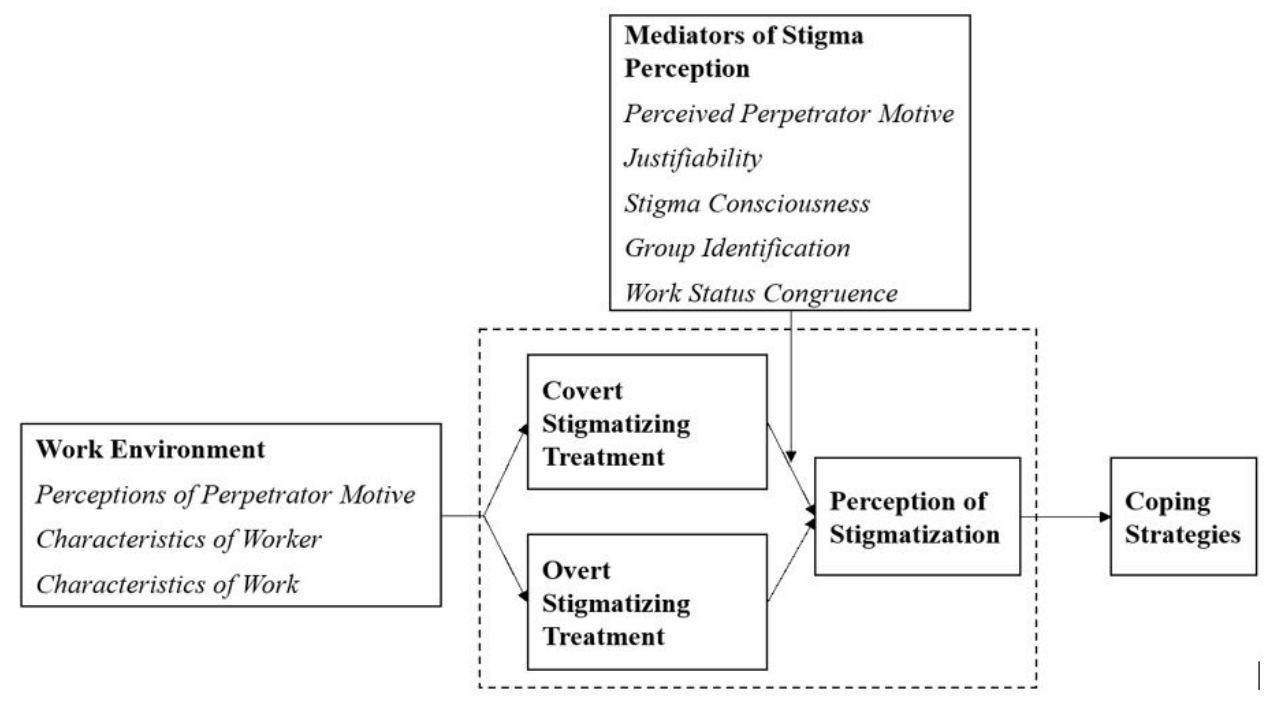

Source: Adopted from Boyce et al. (2007). 


\section{Understanding Temporary Agency Work in Germany}

In Germany, temporary work represents a highly dynamic branch of employment; since 1991, the number of TAWs has quintupled in size up to more than one million. After slightly decreasing, there are currently 948,000 TAWs (BA 2020). In relation to the total population, Germany is one of ten countries worldwide that have the highest percentage of TAWs (Flemnitz 2018). Agency work is most common within the manufacturing sector, although the service sector is gaining importance (Keller and Seifert 2013). Originally functioning as a service provider primarily for metal and electrical-related jobs, temporary agency work is now relevant for a broader spectrum of activities (Schwaab and Durian 2017). From an organizational perspective, the use of temporary agency work mainly aims at productivity and performance enhancement. Holst, Nachtwey, and Dörre (2010) identified three different usage strategies in German client companies serving this objective: ad-hoc assignment, usage as flexibility buffer, and strategic use. The strategies differ in the quantity of use, the qualification and working tasks of the TAW, and the impact on job security and status of the permanent workforce. Depending on the client firm, the various strategies result in different interactions between permanent employees and TAWs. Particularly in client firms aiming to create a competitive work environment between permanent workers and TAWs, interpersonal conflict is to be expected (Becker 2015). A common employment strategy seems to be the assignment of more demanding tasks to permanent employees while giving TAWs simpler tasks. This not only strengthens the permanent workers' feelings of superiority but also provides a breeding ground for tense relationships between the two groups of workers and evokes an informal hierarchy (Rybnikova and Cardone 2018). As mentioned before, TAWs in Germa- ny often occupy low-skilled jobs (BA 2020). In line with that, the proportion of TAWs without any vocational qualification $(31 \%)$ is almost twice as high as the proportion of all employed people without a vocational qualification (BA 2020). Qualified work, on the other hand, is carried out only by a very small number of TAWs (Schwaab and Durian 2017). However, there are also highly-skilled employees working as temporaries, but fewer of them. Only $10 \%$ of all TAWs possess a university degree (BA 2020). Across all job-skill levels, TAWs are disadvantaged with regard to wages. On average, a TAW in the helper sector earns $28 \%$ less than permanently employed workers in the same sector. TAWs in the specialist sector still earn $24 \%$ less, and those in the academic sector $17 \%$ less compared to their permanently employed colleagues (BA 2020). Considering public discourse on temporary agency work in Germany, one can perceive this employment status as socially tainted, considered less prestigious, and with poorer working conditions than permanent workers (Summers et al. 2018; Thomson and Grandy 2018). This negative image is additionally fueled by the argument that temporary agency work replaces permanent jobs and is used by companies to maximize profits and exploit the workforce (Sitte and Lehmann 2013). There are positive effects of temporary agency work acknowledged in public discussions, such as the improvement of organizational flexibility or eventually bringing unemployed people back into the job market (Sitte and Lehmann 2013). However, the negative image of temporary work dominates the discourse in Germany (Flemnitz 2018). Consequently, TAWs often have to deal with problems surrounding social recognition within organizations and society.

\section{Material and Methods}

This study is based on a qualitative research design and analyzes data from 16 interviews with people working 
for independent temporary employment firms. After several phases of data gathering, data collection ended in 2018. TAWs were contacted via three different channels: a temporary employment agency, a direct request to a client firm, and Xing® (a social network for professional contacts within German-speaking regions). The sample included eleven men and five women. This imbalance in favor of male interviewees can be explained by the structure of employment in Germany. As most client firms still represent male-dominated working sectors (Keller and Seifert 2013), temporary agency work in Germany is, in contrast to other countries, a male-dominated branch consisting of about 70\% male employees (BA 2020). For this reason, our sample represents the sex division of TAWs as they exist in the contemporary German labor market. The age of the interviewees ranged from 20 to 62 years. They had worked for temporary employment agencies for two months up to 20 years. The sample consists of seven TAWs employed in low-skilled jobs as helpers and nine employed in high-skilled jobs as specialists and academics. This heterogeneous sample of less or more experienced workers, men and women, older and younger people, as well as those employed in low- and high-skilled jobs enabled us to gain rich insights into the various facets of TAWs' perception and experiences of stigmatization (see Table 1). To ensure a low threshold for participation in the interviews, we tried to provide the most convenient and comfortable settings for the respective interviewees. Accordingly, four interviews took place via telephone and twelve in person. The interviews lasted between 30 and 60 minutes; they were recorded, entirely transcribed, and anonymized (Davidson 2009; Dresing, Pehl, and Schmieder 2015). The interviews aimed at the understanding of TAWs' experiences while being assigned to their client firm(s) and included questions about working conditions in the interviewee's current client firm and their respective expectations. They also covered treatment by permanently employed colleagues and management, as well as the perceptions of poor treatment linked to the interviewee's employment status. Other topics included the visibility of working status, as well as behavioral consequences and possible coping strategies.

\section{Table 1. Interview sample}

\begin{tabular}{|c|c|c|c|c|c|c|}
\hline No. & Job skill-level & Employment position & Job title & Sex & Age & Employment duration as a TAW \\
\hline 1 & Low-skilled & Helper & Production assistant & $\mathrm{m}$ & 48 & 2 years \\
\hline 2 & Low-skilled & Helper & Forklift driver & $\mathrm{m}$ & 33 & 2 years \\
\hline 3 & Low-skilled & Helper & Production assistant & $\mathrm{m}$ & 49 & 2 years \\
\hline 4 & Low-skilled & Helper & Production assistant & $\mathrm{m}$ & 50 & 4 years \\
\hline 5 & Low-skilled & Helper & Production assistant & $\mathrm{f}$ & 47 & 3.5 years \\
\hline 6 & Low-skilled & Helper & Production assistant & $\mathrm{m}$ & 62 & 20 years \\
\hline 7 & Low-skilled & Helper & Production assistant & $\mathrm{f}$ & 45 & 4 years \\
\hline 8 & High-skilled & Specialist & Automotive merchant & $\mathrm{f}$ & 20 & year \\
\hline 9 & High-skilled & Specialist & HR administrator & $\mathrm{f}$ & 27 & 0.5 year \\
\hline 10 & High-skilled & Specialist & Mechanical technician & $\mathrm{m}$ & 37 & 3 years \\
\hline 11 & High-skilled & Academic & Project engineer & $\mathrm{m}$ & 27 & 1.5 years \\
\hline 12 & High-skilled & Academic & Project technologist & $\mathrm{f}$ & 27 & 0.5 year \\
\hline 13 & High-skilled & Academic & Logistics planner & $\mathrm{m}$ & 29 & 3.5 years \\
\hline 14 & High-skilled & Academic & Development engineer & $\mathrm{m}$ & 34 & 3 years \\
\hline 15 & High-skilled & Academic & Technical project manager & $\mathrm{m}$ & 28 & 0.5 year \\
\hline 16 & High-skilled & Academic & Technical project manager & $\mathrm{m}$ & 30 & 2 years \\
\hline
\end{tabular}

Source: Self-elaboration. 
The material was analyzed by using qualitative content analysis (Mayring 2014). As was mentioned above, the study is based on the framework shown in Figure 1 and mainly relies on the four key categories stemming from the stigmatization model developed by Boyce and colleagues (2007): work environment, stigmatizing treatment, perception of stigma, and coping strategies. Whereas the initial coding followed these categories in a deductive manner, a second step also included inductive subcategory building. This means that we applied a mixed approach for categorization. Thus, we inductively extended the original analytical framework based on empirical evidence for additional interdependencies (Table 2). The basic coding scheme based on these findings is presented below, as well as in the discussion section where we also conceptualize our proposition of a revised model.

\section{Table 2. Coding overview}

\section{Main- and subcategories}

Explanation

This category describes how client firms influence the stigma experiences of

Work environment

- Characteristics of the worker

- Characteristics of the work environment

- Perceived perpetrator motives

Stigmatizing treatment

- Forms of stigmatizing treatment

- No stigmatizing treatment
TAWs depending on their strategy of use and organizational practices in dealing with TAWs. This category also illustrates the perpetrator motives behind the stigmatizing treatment of TAWs.

This category includes all forms of stigmatizing treatment experienced, as well as all statements indicating an absence of stigmatizing treatment in client firms reported by TAWs.

\section{Examples}

"everything was explained to me in detail, I could participate in everything, there were really no restrictions and that was really nice. You really noticed that this is also a bit of corporate philosophy.

You didn't feel excluded." [Int.9S]

"The other employees didn't even know that I was from a temporary employment agency. They thought I was a permanent employee. But, when I said it, the behaviors towards me didn't change." [Int.11A]

Perception of stigma

- Stigma consciousness

- Justifiability

- Group identification

This category includes TAWs' perceptions of poor treatment linked to their working status and the rationales they apply to those experiences.

This category includes statements of how TAWs deal with experiences of stigmatizing treatment.
"Why should a temp do clean, pleasant work and the permanent employee bend and work in the mud? That's not what you'd expect, would you?" [Int.1H]

"But, it's simply a system that I don't want to work for and that's why I'm looking for a long-term permanent position." [Int.16A]

Source: Self-elaboration.

To address possible claims of intersubjective comprehensibility and validity, theory-driven and computer-aided data analysis has been carried out using software for qualitative data analysis (MAXQDAC).
To sustain a high standard of qualitative investigation, a triangulation strategy was applied: investigator triangulation (Flick 2011; 2018). All three authors were equally involved in the analysis; they cross- 
checked the coding and discussed their interpretations on a regular basis (Kuckartz and Rädiker 2019).

\section{Results}

In the following section, the findings of the empirical study will be described. Particular differences between TAWs employed in low-skilled jobs as helpers and those employed in high-skilled jobs as specialists or academics are highlighted and-in addition-critically reflected in the discussion section of the paper.

\section{Work Environment}

Our findings reveal that client firms differ in how they organize and define the work arrangements of TAWs, as well as their positions within the organization. The client firms' strategy, along with their history of use, shapes the work environment on several levels. Depending on the field of employment and on basic attitude, to treat TAWs for their period of use as members of the organization or as an external group, client firms either try to keep the differences between temporary and permanent employees to a minimum or highlight these same differences. Highlighting differences can take place at the artifact level (i.e., clothes, email addresses, access cards), by dividing tasks, as well as participation in organizational events and benefits that often work to the disadvantage of TAWs.

What I mentioned is that external employees are treated like guests at best. That you aren't allowed to park in the company parking lot, but only in the guest parking lot is an example. But, not the one for the special guests, which is right in front of the entrance, but the one on the other side of the company site. [Int.14A]
Through these practices, client firms can increase the visibility of employment status and facilitate differentiating TAWs. Visibly and externally perceptible differences, our results suggest, support the emergence of informal hierarchies and status differences. A common experience shared by our interviewees across different skill levels was the assignment of more pleasant, more important tasks to permanent employees and of less pleasant tasks to TAWs. Thereby TAWs become constructed as an inferior, subordinate group compared to the core workers. The resulting imbalance of power in favor of the permanent employees opens up opportunities for the permanent employees to act as informal superiors vis-à-vis the temporary workforce. How an interviewee reports, there are colleagues who treat the TAWs on equal footing. Nevertheless, there are also such kinds of permanent employees who are of the opinion that they are superior to TAWs. For example, this is expressed by the fact that no objections are accepted (Int.2H). As a result, TAWs receive commands from permanent employees and are pressured to at least partially meet their expectations. Our interview partners suspect that permanent employees see an opportunity in the employment of TAWs, which consists of the possibility to improve their work environment. On the one hand, this can be achieved by passing on unpleasant tasks to TAWs.

When it comes to the unpleasant tasks, which come up every now and then. Then the regularly employed colleague says: "I don't need to do that, that's what we have the temps for!" [Int.1H]

On the other hand, permanent employees might be able to improve their situation by using TAWs as buffers who, due to their independence from the client firm, address unpleasant issues in the name of per- 
manent employees. Nevertheless, not all client firms equally enhance the visibility of employment status. Particularly in employment sectors with higher qualification requirements, some client firms, apart from discreet hints in their email signature, did not draw attention to employment status and tried not to strengthen the differentiation between the core workforce and TAWs. Interviewee 15 even reported having had experienced interactions with permanently employed colleagues from the client firm who did not know that he was employed via a temporary employment agency and who stated their regrets when his work arrangement with the client firm ended. Some client firms also actively support the equal treatment of TAWs within their walls:

There was a company guideline that I read, and it said that "Temporary workers are to be treated like coworkers, so there should be no difference." And if the company serves as a good example, then the employees will see this with different eyes and will implement it accordingly. [Int.9S]

This policy was noticed and well-respected by TAWs. It further represents one example of how client firms can shape the work environment and work relationships with little effort.

However, unlike these positive experiences, our results show that most of the temporary employees interviewed experience less harmonious relationships with the permanent employees at their client firm. Client firm policies shape the relationships between TAWs and the core workforce by pre-structuring those relationships with an atmosphere either of competition and mistrust or of equality and common interests. Our interviewees stated that their poor treatment by permanent workers might be based on several different fears. In the case of
TAWs in low-skilled jobs, permanent workers' fears concerned mainly status loss linked to possible decreased productivity from working with the untrained, unqualified TAWs in their team. Fears of job loss through competition with TAWs, as well as an expected increased workload due to the additional training of newcomers were perceived motives for permanent employees' poor treatment towards TAWs across the different skill levels. Additionally, highly-skilled TAWs in the academic sector perceived permanent workers' fear concerning the loss of know-how as a competitive advantage of the client firm as a possible motive for their poor behavior towards TAWs. Based on the work environment in which TAWs have their first experiences, our findings suggest that they become more or less likely to perceive their employment status as something negative. Experiences in a work environment that is rather exclusive and discriminatory towards TAWs might leave them "branded children" (Int.10S) who will be more likely to suffer because of their employment status.

\section{Stigmatizing Treatment}

Focusing now on the question of what forms of stigmatizing treatment TAWs experience, it becomes obvious that no clear boundary can be drawn between overt and covert forms of stigmatization. Nevertheless, there are a few clearly identifiable examples of such forms of stigmatization; however, within the majority of reported experiences, the boundary becomes blurred. An undisputedly overt form of stigmatization is illustrated clearly in the following sample statement:

During the meeting, it became clear that various approaches weren't correct. So, I said to myself: "You can't leave it like that, because it's simply wrong from 
a planning point of view." Well, then I mentioned it and, in that context, I was told to keep my mouth shut, that I was only a TAW. In front of all the others! [Int.13A]

Even in high-skilled jobs, employment status is used to prevent employee resistance in problematic situations. By highlighting the lack of affiliation with the company, TAWs' contributions within the work environment are devalued if they do not work in the favor of their permanent co-workers or management. Nevertheless, it must be pointed out that interviewee 13 represents an extreme case within the surveyed interviews. Here, TAWs were not allowed to share their lunchtime with permanent employees in the canteen and instead had to have their lunch in their office. They were excluded from meetings, had no access to work-related training, and received less work-related information compared to permanent workers (Int.13A). So, forms of distinction in more highly qualified sectors are less visible, but still exist. In knowledge-intensive industries, this is problematic not only for the workers affected but also for the company in which TAWs with no access to the necessary information are rarely able to perform their tasks to a high standard. As previously mentioned, the boundary between overt and covert stigmatization is becoming predominantly blurred. So, being called a TAW can itself be perceived as overt stigmatizing treatment when the term is perceived to be linked to degrading features.

The only thing that bothered me was that a colleague in my office was always talking about me as a "temporary worker," and I find the term "temporary worker" so outdated and a bit degrading. [Int.9S]

For persons employed in temporary work, terms that are more appreciative, for example, a "person who temporarily assists," are more desirable (Int.9S). This may seem banal at first glance, but for people with low resilience, it is an important and influential factor for their self-esteem within a work context. This situation is similar to the case of interviewee 14. Here, only permanent workers, not TAWs, are allowed to state their academic titles in email signatures (Int.14A). This is a mechanism for enhancing the status differences between permanent workers and TAWs, including negative consequences for both parties, employers and employees. According to our interviews, financial disadvantages are also reflected as stigmatizing treatment. Interviewee 10 stated that only TAWs who are on loan to the client firm for nine months reach the same wage level as workers with the same qualifications. However, only a few TAWs are able to overcome this obstacle, as they often leave the client firm before the nine months are reached. Hence, legal regulations on equal pay are thwarted by the client companies, which, in turn, creates additional stigmatization for TAWs. Interviewee 16 perceived the financial disadvantages as discriminatory practices, and he feels obliged to ask for his rights and perceives the client firm as being without understanding. Instead, these firms develop strategies to avoid the legal regulations of equal pay (Int.16A). Hence, there are certainly financial disadvantages even in more highly qualified jobs, but payment can still be perceived as "good," such as in the case of interviewee 15. It depends on both the temporary employment agency, as well as the client firm (Int.15A, Int.16A). The simultaneous dependence on two separate companies has further disadvantages for TAWs. Being excluded from, for example, a Christmas party is legitimized by legal restrictions (Int.12A). TAWs in this client firm are not allowed to attend more than one company event per year. Ergo, if they participate in an event hosted by the temporary employ- 
ment agency, attending the client's Christmas and summer parties is considered taboo (Int.12A). This was subsequently followed by a further finding that no defined contacts, linked to a lack of clarification of responsibilities for TAWs, in the client firm are perceived as a form of marginalization because no one explicitly cares about helping TAWs integrate into their new working environment (Int.8S). This is problematic not only for the TAWs affected but also for the company in which TAWs with no clear integration into their new working environment are less able to fulfill their tasks from the beginning. In the field of low-skilled jobs, open forms of stigmatization are often associated with the assignment of unpleasant tasks. Moreover, the language used here seems to be "rougher" and easily might turn into actual chicanery and bullying. This, in the eyes of an interviewee, requires a certain physical constitution, as well as a certain degree of resilience on the part of TAWs:

For me, temporary work is almost like its own profession, which not everyone is suitable for. As a temporary worker, you have to be quite tough, and you have to want that! [Int.1H]

If that were not enough, TAWs not only have to do the "dirty work," they are also deliberately given unpopular, difficult tasks:

There's an older man with us...I think they treat him very much... they give him everything they don't want to do. Then he has to lift the glass and put it on the car, and if you do that all day long, you're beaten! [Int.4H]

But, this is just the tip of the iceberg. Another form of stigmatization is being assigned to dangerous tasks where the TAW is not aware of the risks (Int.1H).
It seems that permanent employees exploit the inexperience of TAWs. As already mentioned above, they do this in particular to avoid unpleasant tasks and to simply delegate away parts of their work to them (Int.4H). Additionally, depending on the respective company, working hours are very strictly monitored. The slightest break or interruption is noticed, and even going to the bathroom is suspiciously observed (Int.6H).

Many were there only for two days and then left. They don't get the hang of it. I mean, it really gets you when you know that everyone's looking at you...that you don't stand around, that you're in motion, that you don't blabber. [Int.6H]

Furthermore, certain privileges and benefits, such as free meals, are simply not available for TAWs within the low qualification sector (Int.2H). Other forms of open stigmatization in this sector include verbal attacks or deliberately ignoring legal regulations.

That's how they hold the pistol to your head. Once, I had a situation when I was supposed to work the night shift. At noon they call me, saying I've to switch to an earlier shift. Of course, I know there has to be a break of eleven hours or so. And they don't give a damn! They said: "You want to work, so be here immediately. If not, then you don't need to come here tomorrow anyways!" [Int.2H]

In contrast to the low appreciation of skills within the helper sector, TAWs in higher-skilled jobs encounter another problem tied to expectations. As external employees whose relationships within the client firm are less pronounced, they are expected to openly address problems and fight battles with management for their permanently employed colleagues who are at risk of losing status (Int.9S). However, in 
higher-skilled areas, TAWs have to struggle with stigmatization in the form of financial disadvantages, too. A lower salary, as well as a lower bonus or none at all, are perceived as a significant difference between permanent workers and TAWs (Int.9S). Now, after clearly open as well as blurred forms of stigmatizing treatment have been exemplified, the logical next step is to consider clearly covert forms of stigmatization. An undisputedly covert form of stigmatization is illustrated by the following statement from an interview:

You have to say that when you went through the factory as a temporary worker and said "Good morning" to someone, you didn't necessarily have to expect that something would come back. [Int.13A]

As a result, TAWs are partly ignored by the permanent workforce, or at least they assume that they are being avoided. On the one hand, there is a perceptible increase in cohesion among permanent employees. On the other hand, TAWs represent newcomers and do not benefit from existing group cohesion (Int.10S). Interviewee 16 also lacks a sense of belonging. He further reports that all agreements that apply to permanent workers are not valid for TAWs and are always subject to renegotiations (Int.16A). Regardless of his qualifications, interviewee 14 was treated as less qualified, was given special attention by the permanent staff, and his suggestions were not taken into account (Int.14A). Interviewee 2 assumes that the stereotypes that exist in the minds of the permanent workforce are difficult to overcome:

prejudices exist anyway. You're a temp standing in front of a qualified permanent employee. And he thinks: "Well, he might be okay, but he's one sandwich short of a picnic!" [Int.2H]
It is apparent that there are fewer discrepancies between TAWs in high- and low-skilled jobs within covert stigma than within overt stigma. Lastly, what this research should not ignore is that TAWs also report the absence of stigmatizing treatment. Apart from financial differences and a marginal perception of the position as not a fully-fledged member of the company, temporary employment can also be perceived as a good model by those affected. Certain efforts on the part of the company, such as a good presentation of the company at the beginning of the assignment or philosophy of equal treatment, contribute to this.

I could participate in everything, there were really no restrictions and that was really nice. You really noticed that this is also a bit of corporate philosophy. You didn't feel excluded. [Int.9S]

In the case of interviewee 12, the use of TAWs is deeply embedded in the firm's history, and the firm constantly uses a high number of TAWs to ensure productivity, which is why the permanent members are used to working together with TAWs and do not perceive them as a threat, but rather as the necessary support. There is even a feeling of solidarity towards the TAWs among the permanent staff, or at least this is interviewee 12's perception (Int.12A). Temporary work can also be understood as a positive context in which problems can be solved with a flexible change of workplace. This perspective highlights aspects of work stability that seem to go hand in hand with the conscious choice of this employment status mentioned by TAWs in high-skilled jobs (Int.8S). On the whole, stigmatization does not occur at all workplaces. As expected, it depends on the company, organizational culture, and colleagues (Int.2H). There are also depictions by TAWs who experienced their day-to-day work as equal to 
permanent workers (Int.5H). There are companies striving to integrate TAWs. Hence, TAWs are invited to corporate events and parties, they can participate in staff meetings, and they get presents and even bonuses (Int.6H). This, again, supports the impression that stigmatization very much depends on the worker's specific context.

\section{Stigma Perception}

Our findings showed an ambivalent picture of how TAWs perceive their employment status and related stigmatization. TAWs in jobs requiring higher qualifications experienced poor treatment linked to their employment status in person-to-person interactions less often than TAWs in low-skilled jobs. However, they perceived their employment status as stigmatized on a societal level based on the negative image of temporary work in public discourse. This public stigma may be one reason for TAWs in highly qualified jobs to less openly communicate their employment status to others, even though their personal experiences within client firms are, in most cases, positive.

Well, that's the thing about it. People ask: "What are you doing these days?" Then I say: "Well, I work at [client firm name]." Which is ultimately the case. I've a temporary employment contract...Only that I'm paid from another position. Yeah, right. As I said, I won't say it explicitly now. [Int.11A]

Linked to the negative image of temporary work, TAWs in higher qualified jobs criticize structural disadvantages, addressing issues of unequal pay or being excluded from client firm benefits. Instead, TAWs in the helper sector reported experiencing poor treatment related to their employment status in face-to-face interactions within client firms and perceived themselves as being stigmatized, resulting partly in self-stigmatization. Strong awareness of an existing stigma around temporary work was also expressed by the self-descriptions of these TAWs: "You're a second-class worker, you're a temporary worker. A temporary worker is a temporary worker. Is and will always be!" (Int.3H).

The perceptions of being degraded or placed in an inferior position because of employment status become even more evident when reflecting on their level of training: "and I asked myself: 'Why am I here even though I know I can do better?'” (Int.2H). The perception of being degraded, however, is also an issue that TAWs in more highly qualified jobs have to deal with:

But, obviously, you feel like a fool if you have studied at university for a few years and got a degree, and still receive work from someone who is formally not qualified and treats you like an idiot. [Int.14A]

The perception of structural disadvantages on the part of the majority of TAWs in specialized and academic employment sectors and the perception of interactional stigmatization of the majority of TAWs in the helper sector led to different rationales in TAWs' narratives justifying their experiences in client firms. Across all job skill levels, TAWs argue with a specific market logic that client firms are following when planning to work with temporary employment agencies. For example, one interviewee considers that modern technical production cannot actually be marketable without TAWs because temporary work has developed into a proven method to react in line with the market demands (Int.1H). Within legal restrictions, client firms are able to extend their workforce using TAWs without offering the same benefits they offer their core workforce. 
If there weren't temporary workers, some regular workers would have to do it. But, if you've got the possibility, you take a temp, 'cause this job is easy to learn or instruct. But, that's absolutely normal, that's what I'm here for...Why should a temp do clean, pleasant work and the permanent employee bend and work in the mud? That's not what you'd expect, would you? [Int.1H]

Within these limits, our results suggest that TAWs accept being treated differently without blaming the client firm and its members.

TAWs in high-skilled jobs further refer to the legitimate fears of client companies and their attempts to protect themselves. They argue that client firms develop practices of exclusion concerning information sharing or access rights towards TAWs to protect themselves from the perspective of data or patent law.

When I think about IT and IT security, it's quite understandable. Because permanent employees can be threatened with being fired if they do something stupid, if you look at it like that. The company has more confidence in its permanent employees. I can understand that a bit and I agree with that. [Int.14A]

TAWs in the helper sector mainly use a completely different argument to justify being treated poorly within client firms. They see the negative image of temporary work and the associated negative attitudes of permanent employees towards TAWs as being rooted in a subgroup of TAWs who fit the existing prejudices. Instead of blaming the client firm policies, legal restrictions, or societal discourse, they search for reasons among their own. Hence, they establish some sort of secondary order:
There are two kinds of temporary workers. There are people, I've met enough out there, they really haven't learned anything in life. [Int.3H]

...the cliché isn't far away that there really are alcoholics or people who somehow have difficulties in life, who then also gain a foothold through temporary agency work. [Int.1H]

Although our interviewees clearly distinguish themselves from the group of "bad" TAWs, they assign to a part of their own group attributes such as being lazy, without skills, or acting less committed, which all justify the stigmatizing treatment, or at least the existing prejudices, towards them. Moreover, poor behavior towards TAWs is simply seen as an innately human characteristic, almost some kind of anthropological constant: “Well, it's human, I'd say...After all, man is a pig!" (Int.4H). Our findings suggest that the stigma consciousness of TAWs across different job skill levels differs according to the rationales to justify the status quo. Disadvantages at the monetary level associated with employment status and a negative image of the temporary employment industry, in general, play a more significant role in the narratives of TAWs in high-skilled jobs than in those employed in lesser-qualified jobs. In low-skilled jobs, the interactional, immaterial level tends to come to the surface, which can be attributed, among other things, to the lack of alternatives for those affected. In contrast to academics or specialists, TAWs in helper roles do not expect their situation to change in the near future and are more likely to accept their status as a TAW as part of their identity.

\section{Coping Strategies}

Turning now to the question of how TAWs individually cope with stigmatizing experiences, one can 
observe different strategies. Whereas companies use the threat of immediate lay-off, TAWs also make use of the opportunity to leave a company:

I said: “Go, find yourself another stupid! If you don't like it, you get my timesheet, you can sign it and goodbye." Short, concise, functional, clear. [Int.3H]

A similar strategy is to give up temporary work to find a "regular" job. Interestingly, the perspective of potentially leaving a client firm could be found in all sectors, but it seems to be even more important for highly qualified TAWs. Here, temporary work is actively used as a bridge to professional life, such as to gain experience after graduating from a university. The perspective of moving from temporary employment to normal employment quite easily or within a relatively short period suggests that people identify less strongly with their status as TAWs. In the same way, impression management is one strategy used in high-skilled jobs to avoid being noticed as a TAW or in any negative manner. What appears to be very crucial here is the impression of having control of the situation. This is reflected in the perception of having chosen the work arrangement and the feeling that it serves a certain purpose:

You have somehow in the back of your mind, maybe you have the chance to get a foothold there, that means you try hard and try to do all the tasks that come up...I've used the temporary work for myself, I've acquired a lot of knowledge. [Int.13A]

This supports the idea that TAWs in high-skilled jobs try to avoid any form of identification with their employment status. This is also supported by the fact that this group shows no form of self-stigmatization. For the highly qualified, temporary work is considered to be just a short phase or a step- ping stone. In that regard, TAWs in the sectors with higher qualifications see the possibilities of training within client companies as further privileges that are rarely made accessible to TAWs in the low-qualified helper sector. Even though some of the TAWs in the low-skilled sector try to gain skills and knowledge, such as reading hand-outs and leaflets or willingly taking up new tasks, they also do it with another objective:

I'm paid for my time anyway and if they say now perhaps you could do this or do that, then I'll do that. It's rewarding for me, you know? 'Cause I learn something, too. [Int.6H]

This appears to be a form of assimilation, actively integrating oneself thus gradually overcoming the role of TAW. For example, one interviewee describes how he volunteered to step in for another co-worker to help him get a day off. On this occasion, he asked for a crash course to be able to take over this colleague's tasks. In line with these findings is a strategy for making sense of one's respective work, or feeling like one's work is meaningful.

What I also think is a very liberating factor, and this is my deep personal impression, it is that you basically do an honest job where you are needed. [Int.1H]

When it comes to verbal discrimination, one coping strategy is to perceive it as humor, or as comments that are not to be understood as real attacks towards the TAWs, especially within highly qualified fields. This is a rather remarkable outcome, as this perception might be a mechanism of highly qualified TAWs protecting their status and self-worth against discrimination. On the other hand, a coping strategy across all sectors for dealing with poor treatment is to simply ignore it. This can also include a general 
stance towards temporary work. One of the interviewees describes his attitude as follows:

I believe I go there to work, I don't care what people think about me. 'Cause after work I'm with my people, so this doesn't matter anymore. [Int.2H]

The missing affiliation to the company and the opportunity to quit at any time also gives TAWs the opportunity to speak frankly to their superiors:

A temporary worker sometimes has a certain distance, I can talk to the really big boss without any hesitation. I also sometimes had the impression that he likes it when he gets straightforward feedback from the bottom. [Int.1H]

Also, the perspective of being in a company for only a short period seems to help when it comes to poor treatment and working conditions:

There are companies where I keep telling myself, "You're only a holiday replacement for three to four weeks," so you bear it and it's alright. [Int.6H]

Overall, these results indicate that when it comes to coping strategies, an important factor seems to be individual resilience.

\section{Discussion}

Previous research on temporary agency work emphasized that TAWs, particularly those in low-skilled jobs, are likely to be exposed to stigmatization. However, stigmatization of TAWs employed in highskilled jobs, as well as experiences of stigmatization across different skill levels, have not been treated in much detail. With a focus on low-skilled jobs, existing research provided a rather incomplete picture of stigmatization within the broader field of temporary employment. In contrast to earlier studies, this study considered both TAWs employed in low- and highskilled jobs and has been able to highlight the differences of perceiving and coping with stigmatization. Using and extending Boyce and colleagues' (2007) model of TAW stigmatization enabled a holistic perspective on stigmatization processes in client firms. In the literature, job-related stigma has been associated with negative outcomes for both the individual and the organization. This is exemplified in a study undertaken by Boswell and colleagues (2012:455) who explain how poor treatment towards TAWs and their self-perception as workers with lower status might affect their "work-related attitudes and behaviors which are critical to business operations." Notable are also recent findings with regard to negative effects on TAWs' well-being, health, job satisfaction, and commitment (e.g., Aleksynska 2018; Imhof and Andresen 2018; Stasiowski and Kłobuszewska 2018; Hünefeld et al. 2020). Other studies emphasized organizational losses caused by stigmatization, such as a waste of TAWs' knowledge and skills, as well as a decrease in organizational social capital (Augustsson 2014; 2016; Viitala and Kantola 2016; Wilkin et al. 2018; Winkler and Mahmood 2018). These findings demonstrate the need for better strategies to integrate TAWs to avoid their stigmatization in client firms. This study contributes to research on temporary work and stigmatization by providing knowledge of the multifaceted range of stigmatization experiences in jobs with different skill levels. Thereby the findings may help to develop strategies to avoid negative consequences resulting from this type of stigma. The results show that the stigma experiences of TAWs differ depending on the working environment embedded in different employment sectors. Regardless of qualification level, stigmatization was more of an issue for those TAWs whose employment status visibil- 
ity was reinforced by the client firm. Such problematic measures comprised different clothing, the assignment to inferior tasks, or the spatial separation of office and lunchrooms. These status-reinforcing practices on an artifact level have been explicitly mentioned as means to promote separation between the core workforce and TAWs. One interviewee expressed how the treatment of TAWs drastically changed after a new management board was introduced, which implemented procedures that resulted in a sudden change in the permanent workers' behaviors and gave rise to stigmatizing treatment towards TAWs. Organizational change, such as the change of management board, has been identified as a trigger for growing hostile work environments in previous studies, especially if connected to intensified job insecurity, competition, or role conflict (Skogstad, Matthiesen, and Einarsen 2007; Spagnoli, Balducci, and Fraccaroli 2017). Moreover, prior studies suggest that management and permanent workers may have an interest in keeping the status of TAWs low to maintain their power (Byoung-Hoon and Frenkel 2004; Boyce et al. 2007; Becker 2015). For example, Rybnikova and Cardone (2018) found that the behaviors of core workers depend on whether management policies support or sanction inclusive behaviors towards TAWs. Our study confirms this argument and shows that management that promotes a status-reinforcing atmosphere along with strong differentiation between the two groups endorses permanent workers' tendencies to distance themselves from TAWs. By doing so, management policy provides the basis for stigmatization by legitimizing open discrimination of TAWs across the different skill levels. Several reports have shown that permanent workers seem to face a dilemma when confronted with TAWs. They are framed as outsiders and a threat, but permanent workers need to cooperate with them to perform their jobs (Rybnikova and
Cardone 2018). Consequently, previous findings indicate that the strategic separation and devaluation of TAWs has negative effects on the core workforce, and potentially on the organization itself. With regard to working context, our findings show a blind spot in the previous model of TAW stigmatization (Boyce et al. 2007). An important contextual factor appears to be the role of the temporary employment firm and its relationship with the client firm, as well as with the employed TAW. From the experiences of our interviewees, it became apparent that these relations shape stigma perception. On the one hand, the negotiation between the companies clarifies the basic terms and conditions that pre-structure the TAW's work arrangements. On the other hand, the actions of the temporary employment agency can shape the TAW's perceived level of uncertainty. Our data indicate that TAWs' perception of poor treatment is less severe if their employment agency is supportive when problems arise (i.e., helping to find a new client firm). If the client firm and the temporary employment agency have strong ties and build an alliance to the disadvantage of TAWs, poor treatment in the client firm becomes more serious. These findings are not taken into account in the current stigmatization model and represent a meaningful extension to the theoretical framework for future studies. One unanticipated finding was that the pre-structuring effect the work environment has is evident for all interviewees and across the different skill levels. However, the specific forms of stigmatizing treatment differed according to the worker's position in low- and high-skilled jobs. Basically, we found the forms of stigmatization already highlighted in previous literature (Bosmans et al. 2015a; 2015b; Helfen et al. 2015; Stasiowski and Kłobuszewska 2018), but we were able to identify which of these forms are more relevant in each respective sector. While verbal discrimination (e.g., devaluing the skills and contributions of 
TAWs) and task-related discrimination (e.g., allocation of undesirable activities to TAWs) were more obvious in low-skilled jobs, TAWs employed in highskilled jobs more frequently reported the denial of information or rights-matters that were perceived as a lack of trust. Following the descriptions of the interviewees, the emergence of verbal devaluation in the helper sector can possibly be explained by the generally tougher tone in the manufacturing industry. There seems to be a higher level of politeness in interpersonal interactions in office jobs with higher qualification requirements. However, this sector seems to be open to more subtle forms of stigmatizing treatment. For TAWs in jobs with higher qualification requirements, these experiences led to very uncomfortable situations in the client firm. As our interviews have shown, distrust towards TAWs can easily develop and manifest in exclusionary practices, especially in knowledge-intensive and innovation-driven professions such as engineering. In previous research, there is some evidence suggesting that highly-skilled TAWs' knowledge and skills are not efficiently used in client firms and that their opportunities to contribute to organizational developments are strategically cut off (Augustsson 2014; 2016; Viitala and Kantola 2016). Whereas those studies evaluated potential organizational losses, our findings additionally raise awareness of how holding back information or denial of rights can promote the emergence of stigmatization. Moreover, and quite contrary to the theoretical framework, we found that the boundaries between overt and covert forms of stigmatizations are mostly blurred. According to Boyce and colleagues (2007), overt forms of stigmatization include direct devaluing statements linked to the employment status, whereas covert forms include nonverbal expressions of dislike, practices of social exclusion, and denial of resources or information. Difficulties with this classification arise, however, when attempting to place the empirical findings in this framework. According to this classification, many of the stigmatization experiences reported by the interviewees in our study would have to be classified as covert forms of stigmatization, for example, the exclusion of temporary workers from the canteen. The interviewee himself, however, perceived this as an overt form of stigmatization, which is why we conclude that this classification needs revision. We propose to avoid the strict subdivision of overt and covert forms of stigmatizing treatment, even though differences certainly exist. Particularly for qualitative empirical studies, this solution offers greater flexibility. In addition, our study shows that not only do the forms of stigmatizing treatment differ according to the skill level but there are also major differences in the extent to which stigmatization is perceived at all. We found TAWs to have developed various ways of justifying poor treatment and defining their identity as a TAW, for instance, as an inferior worker. Nevertheless, all of them, albeit to varying degrees, were aware of the stigmatization connected to their employment status. Within the highly qualified employment sector, including specialists and academics, the perception of stigmatization shifted to a more structural level with regard to resource issues such as the denial of information, access rights, or benefits. Interactional stigmatization was rather rare within this sector. Instead, we observed a certain consciousness of being poorly recognized on a societal level. As highlighted in previous studies, temporary work in Germany is socially tainted (Flemnitz 2018). It is interesting to note that this aspect did not play a major role for TAWs in low-skilled jobs, at least in the context of our study. TAWs tended to argue on an interpersonal level and emphasized interaction with permanent employees as central to their experiences of stigmatization. In the current study, justifiability as a mediating factor for the perception of stigmatiza- 
tion (Boyce et al. 2007) proved to be very multifaceted. Although TAWs across all sectors agreed that certain disadvantages of their employment status are due to market logic and the rationality of business organizations, the justification of practices encountered in client firms differed largely. Again, TAWs in high-skilled jobs relied on rather global issues such as legal restrictions and data protection, while TAWs in low-skilled jobs argued that prejudices were the main reason for poor treatment. They even partly confirmed the existence of these prejudices within their ranks. Whereas TAWs in higher qualified employment sectors tended to blame external factors, those in lower qualified sectors indirectly blamed themselves. Compared to specialists and academics, one possible explanation for the more pronounced self-attribution of TAWs in the helper sector can be found in a stronger identification with their employment status. Referring to Boyce and colleagues (2007), TAWs are more likely to sense stigmatization if their employment status is a core part of their identity.

This takes us to the coping mechanisms of TAWs that our study uncovered. Particularly TAWs in high-skilled jobs avoided identifying with their employment status. Our findings show they are more committed to the work activity itself and more likely to perceive temporary work as just a stepping stone, or a short stopover, while pursuing a career. Identification serves to maintain a positive sense of self through self-distinctiveness and self-enhancement. TAWs employed as specialists or academics perceive a greater chance of moving from temporary employment to regular employment and might experience no advantages from integrating their employment status into their core identity. Perceived as a socially tainted work arrangement, classifying themselves as TAW might have negative effects on their sense of self, in contrast to commit to a specific profession (e.g., engineers). To strengthen one's association with contributions and qualifications rather than with employment status as a TAW, another strategy of highskilled workers is impression management. It serves to manage external perceptions and can be used to encourage self-respect and respect from others (Winkler and Mahmood 2018). TAWs highlight that being in this work arrangement only helps them to acquire knowledge and develop business contacts.

In general, for TAWs across all qualification levels, having the perspective of leaving the client firm, whether it is for a better arrangement in another client firm or for a regular job, is a coping strategy that helps them take poor treatment less seriously. However, TAWs in low-skilled jobs often have fewer opportunities to engage in regular employment and their job might also be considered less prestigious compared to high-skilled jobs. This explains why the attachment of low-skilled workers to the TAW category seems more likely here.

However, TAWs employed as helpers also seek to maintain a positive sense of self. In this case, one coping strategy to protect self-distinctiveness and self-enhancement can be seen in downward comparisons within the group of TAWs. In accordance with Kreiner and colleagues (2006), we can state that TAWs in the helper sector show an ambivalent identification with their group. In general, they identify themselves as TAWs, but, at the same time, they do not identify with the inferior parts of the group. These people seemingly confirm prejudices about TAWs, such as being lazy, less committed, or less qualified. Such devaluing comparison processes within one's group can be understood as a form of in-group disidentification that aims to distance oneself from the stigmatized group (Bosmans et al. 2016). In this case, TAWs themselves contribute to the reinforcement of 
prejudices against them. Another coping strategy we found to be mainly relevant to TAWs employed in low-skilled jobs was the valorization of work activity. Perceiving the tasks of TAWs as meaningful contributions to the client firm's success was reported to help TAWs interpret the assignment of less pleasant tasks more positively and to perceive their position within the client firm as relevant. Such reframing tactics have been identified in occupational stigma research on domestic workers (Bosmans et al. 2016). Through reframing, TAWs overwrite the negative aspects of the employment status and infuse them with positive values.

Ultimately, despite job qualification level, TAWs' narratives also showed evidence of downplaying and ignoring poor treatment. Consequently, not all negative experiences in client firms were perceived as stigma- tization; verbal abuse, for instance, was framed as humor, and the exclusionary behavior of permanent employees was simply regarded as irrelevant.

\section{Conclusion}

The purpose of our study was to explore the stigmatization experiences and coping strategies of TAWs employed in both low- and high-skilled jobs. In addition, we critically analyzed the narratives presented by TAWs in regard to the work environments in which these stigmatizing experiences took place. Our findings provided empirical evidence for Boyce and colleagues' (2007) model and simultaneously enriched the framework for further qualitative research. Figure 2 provides our proposed model of TAW stigmatization, based on the ideas of Boyce and colleagues (2007) and with the integration of our empirical findings.

\section{Figure 2. A modified model of TAW stigmatization}

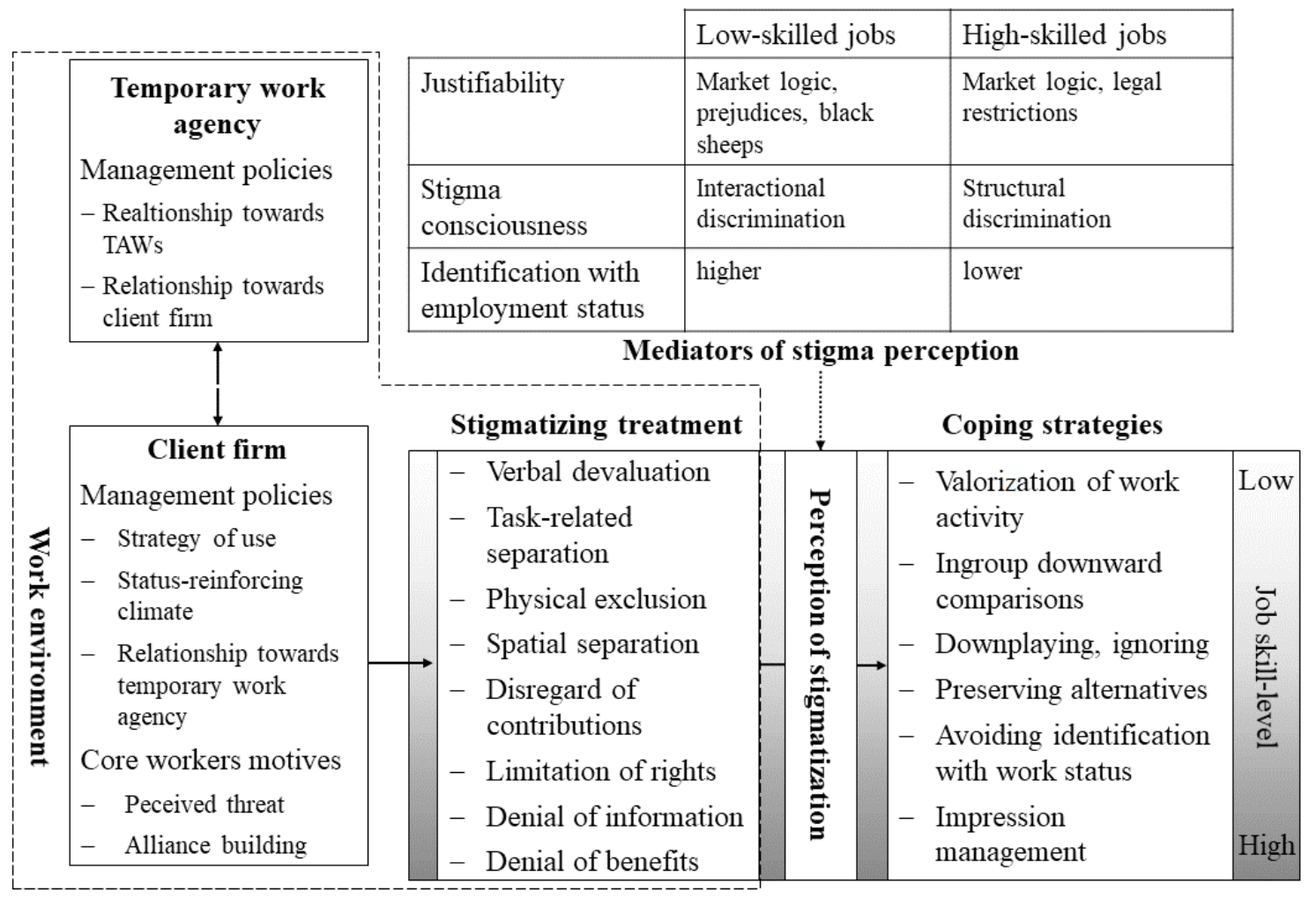

Source: Self-elaboration. 
Although our study provides new and valuable insights, it has several limitations. Our findings reflect the perspective of TAWs themselves; however, including the perspectives of management and permanent workers would have extended our focus and could have helped us dig deeper into questions about power structures, perpetrator motives, and the rationales behind certain practices. Furthermore, our findings represent a snapshot of the period in which our data were collected. In a complex and highly dynamic society, stigmatization in regard to a specific work arrangement might change over time, particularly with revolving societal discourses. Another limitation of this study is the relatively small sample, although the heterogeneity of the interviewees enabled us to identify factors crucial to stigmatization processes. The strength of this study is that it explores the multifaceted range of stigmatization experiences that TAWs experience with regard to the skill level of their position. From a practical perspective, a critical reflection on existing practices of client firms in dealing with TAWs with regard to their effects is recommended. In particular, for client firms employing TAWs in lowskilled jobs, exclusionary practices on an interpersonal level should be reflected and avoided, whereas client firms employing TAWs in high-skilled jobs should strive for more equality on a structural level to achieve the anticipated objectives associated with the use of TAWs. Furthermore, prospective studies could clarify the importance of trust issues in temporary work. Our findings revealed a lack of trust to

\section{References}

Aleksynska, Mariya. 2018. “Temporary Employment, Work Quality, and Job Satisfaction." Journal of Comparative Economics 46(3):722-735. be a crucial factor in the stigma perception of TAWs in high-skilled jobs.

By focusing on the employment status embedded in specific work organizations, we have also chosen to narrow our perspective and exclude other characteristics with the purpose of conducting an in-depth analysis. However, existing literature provides evidence for other drivers of stigmatization practices that go beyond our research focus. On the one hand, leadership styles, psychosocial factors, as well as occupational risks are mentioned as relevant triggers for hostile behaviors in organizations (Feijó et al. 2019). On the other hand, additionally to employment status, several other social categories, such as gender, age, ethnicity, sexual identity, religion, sickness, and obesity, are well-known as the basis for stigmatization in organizational contexts (Thomson and Grandy 2018). Particular emphasis is also placed on the intersection effects of employment status with other categories such as gender or ethnic origin (Einarsen et al. 2011; Salin and Hoel 2013). Consequently, for future studies, it would be intriguing to focus on the intersections between different social categories, such as skill level and migration experiences of TAWs. Current developments show that migrants, particularly refugees, suffer from being placed in inferior positions. Moreover, stigma research has emphasized that ethnic minority groups are segregated into jobs that tend to be stigmatized (He et al. 2019). This is a trend that should be more closely examined in future research.
Augustsson, Gunnar. 2014. “Temporary and Regular Workers Fulfill Their Tasks Side-By-Side, but in Different Learning Conditions." Journal of Workplace Learning 26(2):79-90. 
Augustsson, Gunnar. 2016. “The Client Company Marginally Utilizes the Knowledge of Highly Skilled Temporary Staff." Journal of Education and Work 29(5):519-539.

BA. 2020. Aktuelle Entwicklungen in der Zeitarbeit [Current Developments in Temporary Employment]. Retrieved May 13, 2020 (https:// www.ig-zeitarbeit.de/sites/default/files/redaktion/artikel/2020/Arbeitsmarkt-Deutschland-Zeitarbeit-Aktuelle-Entwicklung.pdf).

Becker, Karina. 2015. "Macht und Gesundheit. Der informelle Handel um die Vernutzung von Arbeitskraft [Power and Health. The Informal Trade about the Use of Labor]." Berliner Journal für Soziologie 25(1-2):161-185.

Benoit, Cecilia, Bill McCarthy, and Mikael Jansson. 2015. “Occupational Stigma and Mental Health: Discrimination and Depression among Front-Line Service Workers." Canadian Public Policy 41(2):61-69.

Benoit, Cecilia et al. 2019. “'The Prostitution Problem': Claims, Evidence, and Policy Outcomes." Archives of Sexual Behavior 48:1905-1923.

Borgogni, Laura, Chiara Consiglio, and Christina Di Tecco. 2016. "Temporary Workers' Satisfaction." Journal of Career Assessment 24(1):86-98.

Bosmans, Kim et al. 2015a. "Temporary Agency Workers as Outsiders: An Application of the Established-Outsider Theory on the Social Relations between Temporary Agency and Permanent Workers." Society, Health \& Vulnerability 6(1):1-23.

Bosmans, Kim et al. 2015b. "Explaining the Relation between Precarious Employment and Mental Well-Being. A Qualitative Study among Temporary Agency Workers." Work 53(2):249-264.

Bosmans, Kim et al. 2016. "Dirty Work, Dirty Worker? Stigmatisation and Coping Strategies among Domestic Workers." Journal of Vocational Behavior 92:54-67.

Boswell, Wendy R. et al. 2012. "Second-Class Citizen? Contract Workers' Perceived Status, Dual Commitment and Intent to Quit." Journal of Vocational Behavior 80:454-463.

Boyce, Anthony S. et al. 2007. “Temporary Worker, Permanent Loser? A Model of the Stigmatization of Temporary Workers." Journal of Management 33(1):5-29.

Bryant, Melanie and Tui McKeown. 2016. "Experts, Outsiders or Strangers? The Self-Positioning of Highly Skilled Contractors." Journal of Management \& Organization 22(3):388-403.
Byoung-Hoon, Lee and Stephen J. Frenkel. 2004. “Divided Workers: Social Relations between Contract and Regular Workers in a Korean Auto Company." Work Employment \& Society 18(3):507-530.

Chambel, Maria J., Filipa Castanheira, and Filipa Sobral. 2016. “Temporary Agency versus Permanent Workers: A Multigroup Analysis of Human Resource Management, Work Engagement and Organizational Commitment." Economic and Industrial Democracy 37(4):665-689.

Crandall, Christian S. 2000. “Ideology and Lay Theories of Stigma: The Justification of Stigmatization." Pp. 126-150 in The Social Psychology of Stigma, edited by T. F. Heatherton et al. New York: Guilford Press.

Davidson, Christina. 2009. "Transcription: Imperatives for Qualitative Research." International Journal of Qualitative Methods 8(2):35-52.

Djurkovic, Nikola. 2018. “Workplace Bullying in Precarious Employment." Pp. 587-613 in Handbooks of Workplace Bullying, Emotional Abuse and Harassment: Vol. 4. Special Topics and Particular Occupations, Professions and Sectors, edited by P. D'Cruz et al. Singapore: Springer.

Dresing, Thorsten, Thorsten Pehl, and Christian Schmieder. 2015. "Manual (on) Transcription: Transcription Conventions, Software Guides and Practical Hints for Qualitative Researchers." 3rd ed. Marburg: Self-published.

Einarsen, Ståle et al. 2011. Bullying and Harassment in the Workplace: Developments in Theory, Research and Practice. 2nd ed. London: Taylor \& Francis.

Feijó, Fernando R. et al. 2019. "Risk Factors for Workplace Bullying: A Systematic Review." International Journal of Environmental Research and Public Health 16(11):19-45.

Flemnitz, Sascha J. 2018. “Employment within the German Sector of Temporary Work Agencies-Employer Perception and Motivational Quality in the Context of the Social Aspects in Relation to the Employment Situation of 'Temp-Workers.'” Doctoral dissertation, Georg-August-Universität: Göttingen.

Flick, Uwe. 2011. Triangulation. 3rd ed. Wiesbaden: VS Verlag für Sozialwissenschaften.

Flick, Uwe. 2018. Doing Triangulation and Mixed Methods. London: Sage. 
Goffman, Erving. 1990. Stigma: Notes on the Management of Spoiled Identity. London: Penguin.

Håkansson, Kristina and Tommy Isidorsson. 2012. “Work Organizational Outcomes of the Use of Temporary Agency Workers." Organization Studies 33(4):487-505.

He, Joyce C. et al. 2019. "Stereotypes at Work: Occupational Stereotypes Predict Race and Gender Segregation in the Workforce." Journal of Vocational Behavior 115:103318.

Helfen, Markus, Andrea Hense, and Manuel Nicklich. 2015. "Organisierte Ungleichheit in der Leiharbeit? [Organized Inequality in Temporary Work?]" German Journal of Industrial Relations 22(3-4):282-304.

Holm, Kristoffer, Eva Torkelson, and Martin Bäckström. 2016. “New Types of Employment, New Ways to Be Uncivil? A Thematic Analysis of Temporary Agency Workers' Exposure to Workplace Incivility." Psychology 7(1):74-84.

Holst, Hajo, Oliver Nachtwey, and Klaus Dörre. 2010. Funktionswandel von Leiharbeit: Neue Nutzungsstrategien und ihre arbeits- und mitbestimmungs politischen Folgen [Functional Change in Temporary Work: New Usage Strategies and Their Consequences for Work and Co-Determination]. Frankfurt: Otto-Brenner-Stiftung.

Hünefeld, Lena, Susanne Gerstenberg, and Joachim Hüffmeier. 2020. "Job Satisfaction and Mental Health of Temporary Agency Workers in Europe: A Systematic Review and Research Agenda." Work Stress 34(1):82-110.

Imhof, Susanne and Maike Andresen. 2018. "Unhappy with Well-Being Research in the Temporary Work Context: Mapping Review and Research Agenda." The International Journal of Human Resource Management 29(1):127-164.

Keller, Berndt and Hartmut Seifert. 2013. "Atypical Employment in Germany. Forms, Development, Patterns." Transfer: European Review of Labour and Research 19(4):457-474.

Keune, Maarten and Marcello Pedaci. 2020. “Trade Union Strategies against Precarious Work: Common Trends and Sectoral Divergence in the EU." European Journal of Industrial Relations 26(2):139-155.

Kreiner, Glenn E., Blake E. Ashforth, and David M. Sluss. 2006. "Identity Dynamics in Occupational Dirty Work: Integrating Social Identity and System Justification Perspectives." Organization Science 17(5):619-636.
Kuckartz, Udo and Stefan Rädiker. 2019. Analyzing Qualitative Data with MAXQDA. Text, Audio, and Video. Cham: Springer.

Kunda, Gideon, Stephen Barley, and James Evans. 2002. “Why Do Contractors Contract? The Experience of Highly Skilled Technical Professionals in a Contingent Labor Market." Industrial and Labor Relations Review 55(2):234-261.

Lange, Stefanie et al. 2019. “Workplace Bullying among Employees in Germany: Prevalence Estimates and the Role of the Perpetrator." International Archives of Occupational and Environmental Health 92(2):237-247.

Link, Bruce G. and Jo Phelan. 2014. "Stigma Power." Social Science and Medicine 103:24-32.

Mayring, Philipp. 2014. Qualitative Content Analysis: Theoretical Foundation, Basic Procedures and Software Solution. Retrieved February 18, 2020 (https://nbn-resolving.org/urn:nbn:de:0168ssoar-395173).

Ortega, Adriana et al. 2009. "Prevalence of Workplace Bullying and Risk Groups: A Representative Population Study." International Archives of Occupational and Environmental Health 82(3):417-426.

Pulignano, Valeria and Nadja Doerflinger. 2013. "A Head with Two Tales: Trade Unions' Influence on Temporary Agency Work in Belgian and German Workplaces." International Journal of Human Resource Management 24(22):4149-4165.

Rybnikova, Irma and Pia Cardone. 2018. “Weder Etablierte noch Außenseiter. Figurationssoziologische Betrachtungen der Leiharbeit [Neither Established nor Outsiders. Figurational Sociological Considerations of Temporary Work]." Managementforschung 28(1):117-149.

Salin, Denise and Helge Hoel. 2013. "Workplace Bullying as a Gendered Phenomenon." Journal of Managerial Psychology 3:235-251.

Schwaab, Markus-Oliver and Ariane Durian, eds. 2017. Zeitarbeit [Temporary Work]. Wiesbaden: Springer Fachmedien.

Selvarajan, Thirumalai T., Jeffrey Slattery, and Donna Y. Stringer. 2015. "Relationship between Gender and Work Related Attitudes: A Study of Temporary Agency Employees." Journal of Business Research 68(9):1919-1927.

Sitte, Bernd and Christian Lehmann. 2013. "Zeitarbeit ist nicht gleich Zeitarbeit: Segmentierung der Branche [Temporary 
Work Is Not Just Temporary Work: Segmentation of the Industry]." Pp. 117-136 in Arbeitszeit - Zeitarbeit [Working Time-Temporary Work], edited by M. Bornewasser and G. Zülch. Wiesbaden: Springer Fachmedien.

Skogstad, Anders, Stig Berge Matthiesen, and Stale Einarsen. 2007. "Organizational Changes: A Precursor of Bullying at Work?" International Journal of Organization Theory \& Behavior 10(1):58-94.

Spagnoli, Paola, Cristian Balducci, and Franco Fraccaroli. 2017. "A Two-Wave Study on Workplace Bullying after Organizational Change: A Moderated Mediation Analysis." Safety Science 100:13-19.

Stasiowski, Jędrzej and Małgorzata Kłobuszewska. 2018. “Does the Context Matter? Labour Market Characteristics and Job Satisfaction among Young European Adults Working on Temporary Contracts." Studies of Transition States and Societies 10(3):51-67.

Summers, James K. et al. 2018. "A Typology of Stigma within Organizations: Access and Treatment Effects." Journal of Organizational Behavior 39(7):853-868.

Thomson, S. Bruce and Gina Grandy, eds. 2018. Stigmas, Work and Organizations. New York: Palgrave Macmillan.
Tyler, Imogen and Tom Slater. 2018. "Rethinking the Sociology of Stigma." Sociological Review 66(4):721-743.

Vallas, Steven and Christopher Prener. 2012. “Dualism, Job Polarization, and the Social Construction of Precarious Work." Work and Occupations 39(4):331-353.

Viitala, Riitta and Jenni Kantola. 2016. “Temporary Agency Workers Shake a Work Community: A Social Capital Perspective." Employee Relations 38(2):147-162.

Volpato, Chiara, Luca Andrighetto, and Cristina Baldissarri. 2017. "Perceptions of Low-Status Workers and the Maintenance of the Social Class Status Quo." Journal of Social Issues 73(1):192-210.

Wilkin, Christa L., Jeroen P. de Jong, and Cristina Rubino. 2018. "Teaming Up with Temps: The Impact of Temporary Workers on Team Social Networks and Effectiveness." European Journal of Work and Organizational Psychology 27(2):204-218.

Winkler, Ingo and Mustafa K. Mahmood. 2018. “Flexible Resources and Adaptable Human Beings-The Identity of Temporary Agency Workers." Journal of Organizational Effectiveness 5(2):142-157.

\section{Citation}

Cardone, Pia, Markus Tümpel, and Christian M. Huber. 2021. "Temporary Employment, Permanent Stigma? Perceptions of Temporary Agency Workers Across Low- and High-Skilled Jobs." Qualitative Sociology Review 17(3):6-33. Retrieved Month, Year (http://www.qualitativesociologyreview.org/ENG/archive_eng.php). DOI: https://doi.org/10.18778/1733-8077.17.3.01 